ARTIGO

DEREVISÃO

\title{
Pés: devemos avaliá-los ao praticar atividade físico-esportiva?
}

\author{
Guilherme Veiga Guimarães ${ }^{1}$, Héldio Fortunato G. Freitas ${ }^{2}$, \\ Paulo Roberto S. Silva ${ }^{1}$ e Luzimar R. Teixeira ${ }^{3}$
}

\section{RESUMO}

Nosso sistema de amortecimento começa no pé, segue para o tornozelo, perna e para o resto do corpo. A cada passada, todo o peso do corpo recai sobre uma dos membros inferiores. Quando caminhamos ou corremos, o problema é basicamente a repetição do mesmo exercício por longos períodos, o que exige um sistema eficiente de amortecimento para diminuir os danos causados pelo constante impacto nas articulações e que, muitas vezes, podem se agravar pelas alterações na estrutura anatômica do pé.

A utilização de calçados apropriados ajuda no funcionamento normal do sistema natural de amortecedores. Além disso, uma avaliação do arco plantar e do tipo da pisada poderá contribuir ainda mais para absorver o impacto nas articulações, uma vez que já existem modelos de calçados adaptados às alterações estruturais do pé.

Palavras-chave: Lesão no pé. Esporte. Biomecânica.

\section{ABSTRACT}

Feet: should we evaluate them when practicing physicalsports activities?

Our system of reduction begins at the foot, then going to the ankle, leg, and to the rest of the body. At each footstep, the whole weight of our body is supported by one leg. When we walk or when we run, our problem is basically the repetition of the same exercise for long periods, which demands an efficient system of reduction to decrease the damage caused by constant impact upon the joints, and many

1. Fisiologista do exercício.

2. Médico.

3. Professor de Educação Física.

Endereço para correspondência:

Guilherme Veiga Guimarães

Rua Dr. Baeta Neves, 98

05444-050 - São Paulo, SP

E-mail: gvguima@usp.br

Rev Bras Med Esporte - Vol. 6, № 2 - Mar/ Abr, 2000 times this can be worsened by alterations in the anatomical structure of foot.

The use of proper shoes helps us in the normal operation of the natural system of shock absorbing. In addition, an evaluation of the plantar arch and the type of gait may contribute further to absorb impact on the joints since shoewear exists that adapt to foot structural alterations.

Key words: Foot injuries. Sports. Biomechanics.

A natureza criou o homem para que se movimente com os pés descalços. Durante a passada, o primeiro contato com o solo é feito pelo calcanhar, a seguir pela borda externa do pé, terminando com a porção anterior do pé e pelos dedos, sendo acompanhado por uma rotação interna da tíbia, com a finalidade de amortecer o impacto (figura 1).

Normalmente nos deslocamos sobre superfícies duras; nosso sistema natural de amortecimento resulta ser insuficiente para absorver o impacto e a utilização de calçados apropriados é fundamental para ajudar no funcionamento normal do sistema natural de amortecedores. Contudo, não existe calçado perfeito, sendo que o fator mais importante é seu bom ajuste. As pessoas devem evitar, por motivos óbvios, os calçados muito apertados e também folgados demais, pois podem provocar lesões de fricção (atrito), além de não proporcionarem estabilidade.

Com relação às atividades físicas e aos esportes, o tipo de calçado depende da modalidade esportiva e do tipo de força exercida sobre os pés.

A caminhada e a corrida são as modalidades em que o calçado interfere diretamente na performance do praticante,

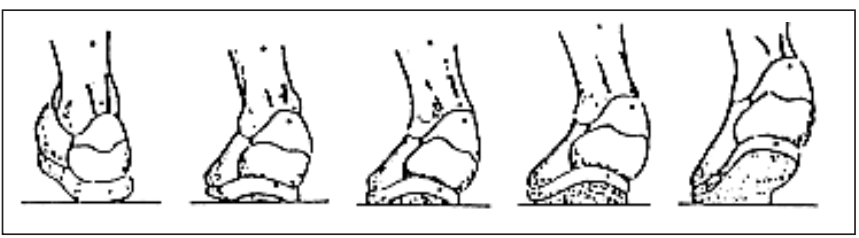

Fig. 1 - Movimento do pé (direito) durante a passada (calcanhar, borda externa, porção anterior dedos e rotação interna da tíbia). 


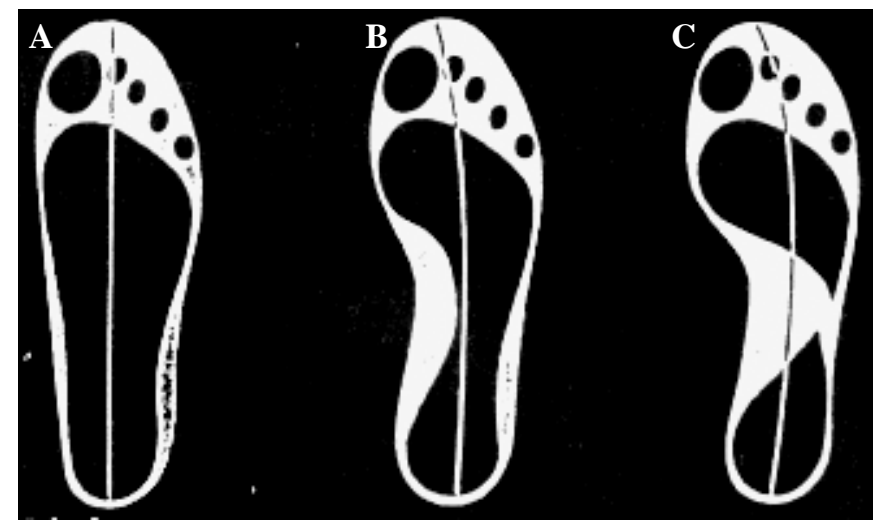

Fig. 2 - Formação do arco plantar: pé plano $(\boldsymbol{A})$, pé normal $(\boldsymbol{B})$ e pé côncavo $(\boldsymbol{C})$

pois, pelo constante movimento em uma única direção, um calçado inadequado pode ocasionar sérios problemas ${ }^{1-3}$.

Grandes distâncias percorridas multiplicam a carga sobre as pernas e os pés e podem ser responsáveis pelas dores musculares nos membros inferiores, que aparecem após a atividade ${ }^{4,5}$. Portanto, a sensação de dor nos músculos dos membros inferiores requer uma investigação imediata para descobrir suas causas. Para isso, alguns fatores importantes devem ser considerados, tais como: excesso de peso; aumento muito rápido da distância a ser percorrida e da carga de treinamento; tipo de terreno, cuidados com os músculos das coxas e das pernas (exercícios de alongamento e fortalecimento); coordenação dos movimentos; cuidados com a postura e se o calçado é adequado.

Se o praticante está atento para estes fatores, é necessário buscar outras causas para as dores musculares nos membros inferiores, sobretudo na estrutura anatômica individual dos pés, pois esta característica vai determinar a forma e a estabilidade da pisada.

Existem três tipos padrões de pés, quanto à formação do arco: pé chato (plano), arcado (côncavo) e normal (figura 2), com quatro tipos de pisadas: neutra, supinador (para fora), pronador (para dentro) e pronador acentuado, sendo que as variações são individuais (figura 3 ).

O pé com pouco ou nenhum arco apresenta excesso de flexibilidade, geralmente com tipo de pisada para dentro, diferente do pé de arco excessivo, que tem baixa flexibilidade, absorve com menos eficiência os impactos com o solo e tem característica de atitude supinadora.

Estudos têm sugerido que uma pisada excessivamente para fora é um importante fator no desenvolvimento de lesões gerais, principalmente em relação aos joelhos ${ }^{6-8}$. Isto é devido, em parte, aos movimentos de inversão/eversão do pé que são transferidos pela articulação do tornozelo em rotações externa/interna da tíbia. Uma excessiva eversão do pé, juntamente com uma excessiva rotação interna

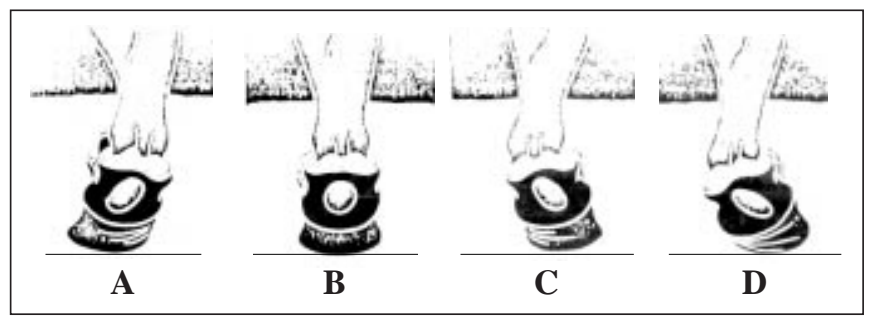

Fig. 3 - Tipo da pisada (pé direito): A, para fora (atitude supinadora); $\boldsymbol{B}$, neutra; $\boldsymbol{C}$, para dentro (atitude pronadora) e $\boldsymbol{D}$, atitude pronadora acentuada.

da tíbia, pode ser considerada uma das maiores razões para o desenvolvimento de lesões no joelho, sendo que até uma moderada rotação entre a tíbia e o fêmur pode alterar a posição da patela no sulco anterior entre os côndilos, lateral e medial, do fêmur ${ }^{5}$.

A indústria do calçado, através de investimentos em pesquisas com atletas corredores, vem desenvolvendo, principalmente na linha esportiva, alguns modelos de calçados com os mais diversos materiais e formas, visando aumentar o conforto, a performance, ao mesmo tempo reduzindo a possibilidade de lesões por sobrecarga ou atrito ${ }^{1,3,9}$.

As novas construções dos tênis visam reduzir a eversão do pé e a rotação interna da tíbia durante o contato com o solo, porém seus reais benefícios ainda continuam contro$\operatorname{versos}^{10}$.

A experiência do Centro de Práticas Esportivas da Universidade de São Paulo (CEPEUSP) em verificar a "saúde" dos pés de alunos, em programa regular de condicionamento físico, e na orientação na aquisição de um calçado mais apropriado, foi realizada em um grupo que iniciou as atividades em agosto de 98.

Foram avaliadas 53 pessoas adultas, sendo 17 do sexo feminino e 36 do sexo masculino, com média de idade de $56,2 \pm 12,6$ anos (40 a 80 anos), sem limitações ortopédicas e iniciantes em programas de condicionamento físico oferecidos pelo CEPEUSP. Os valores médios de peso, estatura e índice de massa corpórea foram respectivamente 81 $\pm 11,2 \mathrm{~kg}, 1,68 \pm 0,05 \mathrm{~m}$ e $28,5 \pm 3,5 \mathrm{~kg} / \mathrm{m}^{2}$.

Todas as avaliações podiátricas foram realizadas no final da tarde, entre 17:00 e 18:30 horas, por uma mesma equipe. Os avaliados receberam orientações para que, no dia do teste, se alimentassem normalmente e mantivessem as atividades diárias.

O teste podiátrico foi realizado em uma folha de papel jornal, estendida sobre uma superfície plana e rígida, com os pés molhados, sem encharcar. $\mathrm{O}$ avaliado foi orientado a dar um passo lento sobre a folha, pisando do calcanhar para os dedos, logo após, foi contornada a impressão que ficou no papel com uma caneta, com a impressão avaliou- 


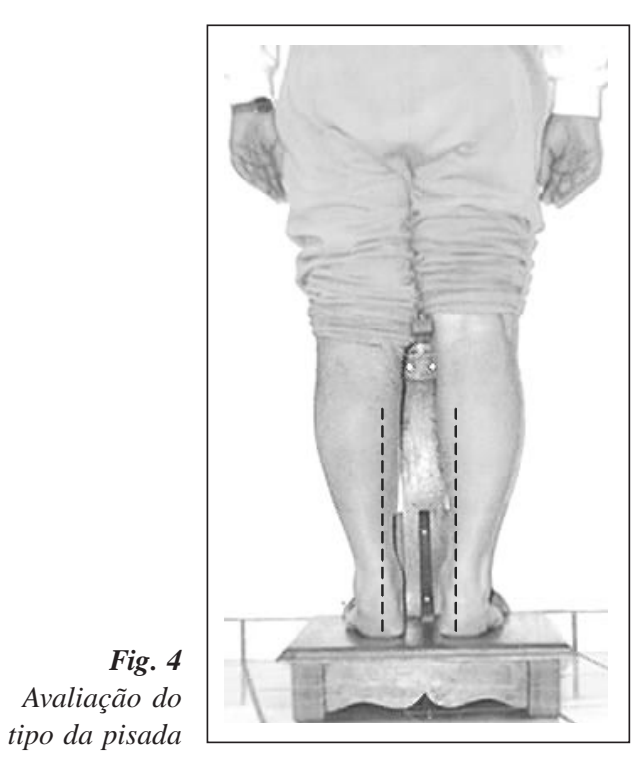

se o tipo de arco plantar. Em seguida, o avaliado ficou na posição ereta sobre uma plataforma plana e rígida, com os pés descalços, paralelos e com um pequeno afastamento lateral das pernas. Com uma máquina fotográfica digital Epson, modelo Photo PC, foi fotografada a parte posterior das pernas. As fotos eram transferidas para um microcomputador Compaq, modelo Presario (5620), com processador Intel Pentium II, e através do software PowerPoint 97 foi avaliado o tipo da pisada (figura 4).

Os resultados mostraram que o arco plantar e o tipo da pisada, assim como já demonstrado em outros estudos ${ }^{1,11}$, são características individuais e independentes (tabela 1). Das 53 pessoas que participaram desta avaliação, 39 (73\%) apresentaram tipo de pisada de atitude pronadora, sendo 12 pessoas com arco plantar normal, 14 com arco côncavo e 13 com arco plano, sendo que apenas 9 (17\%) apresentaram tipo de pisada supinadora (4 com arco normal e $5 \mathrm{com}$ arco côncavo) e $5(9,5 \%)$ com tipo de pisada neutra (todos com arco normal).

De forma geral, com base nos casos mais comuns entre corredores, os fabricantes conseguem atender às características anatômicas dos pés dos esportistas. No entanto, existem pessoas que fogem deste padrão. Estes casos devem ser avaliados por um ortopedista, que poderá dar uma orientação mais adequada.

\section{CONSIDERAÇÕES FINAIS}

Na compra de um par de tênis, deve-se procurar adquirilo no final do dia, quando nossos pés estarão mais inchados comparativamente aos horários da manhã. Além disso, seria interessante fazer uma avaliação podiátrica, para se ter informações sobre o arco plantar e do tipo de pisada,
TABELA 1

Características da estrutura anatômica dos pés de 53 pessoas adultas

\begin{tabular}{lccrr}
\hline \multirow{2}{*}{ Pisada } & \multicolumn{3}{c}{ Arco } & Total \\
\cline { 2 - 4 } & Normal & Côncavo & Plano & \\
Pronadora & 12 & 14 & 13 & 39 \\
Supinadora & 4 & 5 & 0 & 9 \\
Neutra & 5 & 0 & 0 & 5 \\
Total & 21 & 19 & 13 & 53 \\
\hline
\end{tabular}

pois já existem modelos próprios para quem pisa para dentro, gastando mais a borda interna do tênis (atitude pronadora) e para quem pisa para fora, gastando mais a parte externa do tênis (atitude supinadora), assim como para pés com arco normal, plano e côncavo. Outro aspecto importante que se deve considerar na escolha do tênis é com relação ao peso corporal. No caso de peso cima do que seria o ideal, deve-se optar por um calçado que garanta um excelente amortecimento, lembrando que nem sempre o mais caro, o mais colorido e o da moda serão os melhores para os pés. Indicações de amigos leigos ou de balconistas despreparados poderão ocasionar lesões no nosso sistema natural de amortecimento.

\section{REFERÊNCIAS}

1. Omey ML, Micheli LJ. Foot and ankle problems in the young athlete. Med Sci Sports Exerc 1999;31(Suppl):S470-86.

2. Sanatore JR. Functional components of a sport shoe. Orthop Nurs 1996; 15:19-22.

3. Eng J, Pierrynowski MR. The effect of soft foot orthotics on threedimensional lower limb kinematics during walking and running. Phys Ther 1994;74:836-44.

4. Caselli MA, Longobardi SJ. Lower extremity injuries at the New York City Marathon. J Am Podiatr Med Assoc 1997;87:34-7.

5. Grood ES, Davlin LB, Evanski PM. Effectiveness of orthotic shoe inserts in the long-distance runner. Am J Sports Med 1991;19:409-12.

6. Nigg BM, Khan A, Fischer V, Stefanyshyn D. Effect of shoe insert construction on foot and leg movement. Med Sci Sports Exerc 1997; 30:550-5.

7. Clement DB, Taunton JE, Smart GW, McNicol KL. A suvery of overuse running injuries. Physician Sports Med 1981;9:47-58.

8. McCulloch M, Brunt D, Linden DV. The effect of foot orthotics and gait velocity on lower limb kinematics and temporal events of stance. J Orthop Sports Phys Ther 1993;17:2-10.

9. Bates BT, Osternig LR, Mason B, James LS. Foot orthotic device to modify selected aspects of lower extremity mechanics. Am J Sports Med 1979;7:338-42.

10. McPiol TG, Cornwall MW, Rigid versus soft foot orthotics. J Am Podiatr Med Assoc 1991;81:638-42.

11. Clanton TO, Porter. Primary care of foot and ankle injuries in the athlete. Clin Sports Med 1997;16:435-66. 